\title{
MYOSITIS OSSIFICANS: CASE REPORT
}

Vanessa Fraga Mendes (Hospital de Base do Distrito Federal, Brasília, DF, Brasil), Gustavo de Paiva Costa (Hospital de Base do Distrito Federal, Brasília, DF, Brasil), Ravena Fontenele Belchior Cabral (Hospital de Base do Distrito Federal, Brasília, DF, Brasil), Marina Fernandes Oliveira (Hospital de Base do Distrito Federal, Brasília, DF, Brasil)

\section{BACKGROUND}

Myositis Ossificans is a rare disease, characterized by non-neoplastic heterotopic bone formation in soft tissue and skeletal muscle. The disease is established by initial inflammatory process with generation of edema and subsequent calcification of soft tissues.

\section{CASE REPORT}

A 87-year-old female patient, with previous history of hemorrhagic cerebral vascular accident that evolved with restriction to bed and coma. After one year of the event, without trauma, she presented asymmetrical left thigh edema and intense pain on mobilization. Magnetic Resonance showed corticalbased ossification, located in the proximal metaphyseal region of the left femur with cranial extension through the anterior myotendinals of the thigh and hip (vastus medialis, vastus medialis, iliopsoas, proximal margins of the femoral rectus and sartorius), presenting another extensive base cortical shape in the internal and anterior contours of ipsilateral iliac bone, compatible with myositis ossificans (Figure 1, Figure 2, Figure 3 and Figure 4).

The proposed treatment was physiotherapy associated with the use of non-steroidal anti-inflammatory drugs and analgesics. After a few months, the patient evolved with complete improvement of the pain.

\section{CONCLUSION}

Myositis ossificans, even if self-limiting and benign, has a potential for severe functional limitation. The exact etiology remains obscure. Although numerous treatment options have been advocated, therapy remains challenging and must be individualized. In this case, conservative treatment was sufficient for resolution of pain and functional limitation established. 